\section{FutureJournal}

FUTURE STUDIES RESEARCH JOURNAL:

TRENDS AND STRATEGIES
ReVista ofiCial do PROgRama de Mestrado Profissional EM Gestão de Negócios do Profuturo - Programa de Estudos DO FUTURO - DA FIA BUSINESS SCHOOL

Editora Científica: Renata Giovinazzo Spers

Editor Internacional: James Terence Coulter Wright

Editor de Relato Técnico: Daniel Estima de Carvalho

Avaliação: Double Blind Review, pelo SEER/OJS

Revisão: Gramática, normativa e de layout

Recebido em: 07/11/2016 Aprovado em: 29/10/2017

\title{
Programas de Fidelização na Era Digital: Uma Análise Comportamental do Consumidor no Setor de Restaurantes
}

\author{
Roberto Ilidio Lopes Correia \\ Universidade Federal do Rio Janeiro, Brasil \\ robertoilidio@poli.ufrj.br \\ Julia Pinheiro Rizzi \\ FIA - Fundação Instituto de Administração, Brasil \\ juliaprizzi@gmail.com \\ Henrique Senna \\ FIA - Fundação Instituto de Administração, Brasil \\ ricosenna@gmail.com

\section{Guilherme de Paula Florencio} \\ FIA - Fundação Instituto de Administração, Brasil \\ gdpflorencio@gmail.com
}

\section{RESUMO}

Com a importância crescente do mercado de restaurantes e a expressiva expansão da internet no Brasil, soluções de fidelização tendem a migrar para um formato digital, baseada em aplicativos para smartphones em detrimento de soluções baseadas em cartões e carimbos. O presente trabalho tem como objetivo principal quantificar, definir perfil e classificar preferência dos consumidores adeptos, ou com potencial à adesão, a soluções de programas de fidelização para restaurantes. Os números do mercado de restaurantes e de internet no Brasil são levantados para dimensionar o potencial destas soluções de fidelização baseado em internet. A pesquisa predominantemente quantitativa consistiu em aplicar questionário pela internet. Coletou-se 220 respostas válidas, e obteve-se intervalo de confiança de 95\% e erro amostral de 6,6\%. Utilizou-se testes de hipótese ANOVA e modelos de regressão para quantificar a correlação entre variáveis estudadas. Concluiu-se que a variável renda tem a maior capacidade de explicar a adesão a programas de fidelidade para restaurantes, assim como ocorre também em outros segmentos, e que estes programas geram fidelidade comportamental e atitudinal. Além disso, soluções digitais são bem aceitas, abrindo espaço para novas alternativas de programas de fidelidade. 
PALAVRAS-ChaVe: Pesquisa de mercado. Marketing. Fidelização de clientes. Programas de fidelidade.

\title{
Consumer Loyalty Programs in the Digital Age: A Consumer Behavior Analysis in the Restaurant Sector
}

\begin{abstract}
With the growing importance of the restaurant market and the expressive expansion of the internet in Brazil, loyalty solutions tend to migrate to a digital format based on smartphone applications rather than card and stamp based solutions. This study aims to quantify, classify and define profile preferences of fans consumers, or potential accession, loyalty programs solutions for restaurants. The numbers of the restaurant and internet market in Brazil are raised to scale the potential of these internet based loyalty solutions. The predominant quantitative research consisted in applying questionnaires through the Internet. It collected 220 valid responses, and obtained a $95 \%$ confidence interval and sampling error of $6.6 \%$. ANEW hypothesis tests and regression models were used to quantify the correlation between studied variables. It was concluded that the variable income has the greatest capacity to explain adherence to loyalty programs for restaurants, as it also occurs in other segments, and that these programs generate behavioral and attitudinal fidelity. In addition, digital solutions are well accepted, making room for new alternatives to loyalty programs.
\end{abstract}

KEY-WORDS: Market research. Marketing. Customer loyalty. Loyalty programs. 


\section{INTRODUÇÃO}

Programas de fidelização para restaurantes multiplicam-se no Brasil impulsionados pelo crescimento deste mercado e o aumento da competição em períodos de crise. Estes programas, entretanto, utilizam basicamente processos manuais. Observa-se uma tendência destes processos evoluírem e serem suportados por tecnologia da informação, com os usuários utilizando smartphones e tablets, que permitem agregar ainda mais funcionalidades explorando a revolução da internet móvel que ocorre no país.

O crescimento e profissionalização do segmento de restaurantes trouxe maiores desafios aos gestores, que buscam nos programas de fidelização uma alternativa para reter seus clientes. A popularização da internet móvel permite novas possibilidades de soluções, aumentando a praticidade dos processos e abre novas oportunidades de negócios dentro deste mercado.

Por meio de uma pesquisa predominantemente quantitativa, pretendese entender a preferência dos consumidores adeptos, ou com potencial à adesão, a soluções de fidelização para restaurantes, auxiliando gestores na decisão pela melhor solução de fidelização, baseada nos requisitos e características mais relevantes para seu perfil de clientes.

\subsection{PROBLEMA DE PESQUISA}

O mercado de restaurantes vem aumentando sua participação no orçamento das famílias ano a ano no Brasil. Em 2005 representava 1,8\% do PIB, em 2013, quando movimentou 116 bilhões de reais, já representava 2,41\% (ABIA, 2014 e Banco Central do Brasil, 2014). Este crescimento vem acompanhado do aumento da profissionalização do setor, o que acarreta mais investimentos em outros negócios de apoio. Pesquisa da FIESP (2015) e Terzian (2016) apontam que mesmo com as dificuldades econômicas presentes hoje, o setor continua a crescer.

Entre outras estratégias de marketing adotadas pelo setor, programas de fidelidade são amplamente utilizados para reter clientes. Dentro do tema programa de fidelização de clientes em restaurantes, a popularização das tecnologias digitais móveis, baseadas principalmente em smartphones, permitem novas possibilidades de soluções, aumentando a praticidade dos 
processos e consequentemente expandindo este mercado. Para se ter uma dimensão, de 2002 para 2012 o número de linhas de telefones celulares ativos no Brasil foi de 32 milhões para 256 milhões, um aumento de 800\%, e o número de pessoas com acesso à internet no Brasil foi de 14 milhões para 83 milhões, um aumento de 600\% (TELECO, 2015).

Neste contexto, propõe-se analisar o comportamento do consumidor especificamente com relação a programas de fidelidade para restaurantes, em um mercado importante e que constantemente abre novas oportunidades de negócios, de modo a responder à pergunta: qual o perfil de clientes que adotam ou que estão dispostos a adotar os diferentes tipos de programas de fidelização e quais características e requisitos são considerados mais relevantes nestas soluções de fidelização para restaurantes, baseados em tecnologias digitais móveis?

\subsection{OBJETIVOS}

O presente trabalho tem como objetivo principal quantificar, definir perfil e classificar preferência dos consumidores adeptos, ou com potencial à adesão, a soluções de fidelização para restaurantes nos municípios de São Paulo e Rio de Janeiro.

Ao término deste estudo, pretende-se:

- Avaliar a receptividade dos consumidores aos programas de fidelidade de restaurante.

- Comparar a receptividade dos consumidores por programas de fidelidade de diversos segmentos com a receptividade para estas estratégias no segmento de restaurantes.

- Identificar o grau de fidelização (comportamental e afetivo) que os programas têm potencial para alcançar.

\subsection{PRINCIPAIS CONTRIBUIÇÕES}

O presente trabalho tem como finalidade contribuir para a tomada de decisão de gestores do setor de restaurantes, com relação à definição de soluções de fidelização baseada nos requisitos e características mais relevantes 
para seu perfil de clientes. Para isso, o artigo destacará as características socioeconômicas mais relevantes dos adeptos e potenciais adeptos dos diferentes tipos de programas de fidelização. O trabalho trará ainda uma visão sobre o potencial de implementação de soluções digitais, permitindo aos gestores tomar decisões também quanto ao potencial de adoção a essas plataformas.

Por fim, diante da carência de material acadêmico com dados quantitativos sobre o tema programas de fidelidade para restaurantes no Brasil, esta pesquisa contribuirá ainda para expandir o debate científico nessa frente de conhecimento, servindo inclusive de ponto de partida para estudos futuros.

\section{FUNDAMENTAÇÃO TEÓRICA}

\subsection{FIDELIZAÇÃO E PROGRAMAS DE FIDELIZAÇÃO}

Aponta-se o conceito de fidelização como um dos fatores mais relevantes na decisão dos consumidores na escolha de uma marca. Por isto há diversos estudos neste campo, focados na análise do comportamento do consumidor (Jensen \& Hansen, 2006). Criar uma conexão forte e próxima com clientes é o objetivo de qualquer profissional de marketing e muitas vezes a chave para o sucesso de longo prazo, segundo Kotler e Keller (2012), que apontam três tipos de atividades de marketing que as empresas estão utilizando para construir fidelidade e aumentar a retenção: (i) interação com clientes para obter feedbacks; (ii) criação de laços institucionais; e (iii) desenvolvimento de programas de fidelização.

Este último é elaborado para recompensar clientes que compram em quantidades relevantes, o que pode ajudar a construir fidelidade de longo prazo com clientes de alto valor de tempo de vida (CLV), criando oportunidades de vendas cruzadas (Ibid). Tendo como pioneiros as empresas de linhas áreas, hotéis e cartões de crédito, programas de fidelidade têm sido implantados em diversas outras indústrias hoje em dia, como o segmento de restaurantes, alvo do presente estudo.

O conceito de fidelidade pode ser analisado em um plano bidimensional, nesta perspectiva, há um relacionamento entre atitude e 
comportamento. Comportamento de fidelidade é definido como a repetição de compras, enquanto a atitude de fidelidade é definida como o desejo do cliente de manter sua relação com a empresa, independente dos preços mais baixos dos concorrentes, e recomendar seus produtos e serviços (Dick \& Basu, 1994; Larán \& Spinoza, 2004). Este plano bidimensional pode ser apresentado conforme figura 1 abaixo:

\begin{tabular}{|c|c|c|}
\hline \multirow{2}{*}{$\begin{array}{c}\text { Postitude em relação } \\
\text { à marca }\end{array}$} & $\begin{array}{c}\text { Fidelidade } \\
\text { sustentável }\end{array}$ & $\begin{array}{c}\text { Fidelidade } \\
\text { latente }\end{array}$ \\
\cline { 2 - 3 } Negativo & $\begin{array}{c}\text { Fidelidade } \\
\text { falsa }\end{array}$ & $\begin{array}{c}\text { inexistência } \\
\text { de fidelidade }\end{array}$ \\
\cline { 2 - 3 } & Alta Repetição de compra da marca Baixa \\
\hline
\end{tabular}

\section{Figura 1: A taxonomia de fidelidade com base nas dimensões atitude e comportamento}

Fonte: Dick e Basu (1994)

O papel destes programas na construção afetiva e comportamental da fidelidade foi investigada no trabalho de Gómez, Arranz e Cillan (2006). A fim de medir fidelidade atitudinal, os autores analisaram a chave dos elementos de criação de fidelidade de atitude: satisfação, atitude com relação ao varejista, a confiança no varejista, confiança nos produtos ou serviços e envolvimento. A fidelidade de comportamento foi medida em duas variáveis: a compra da marca em estudo e dos concorrentes. Como indicadores, foram utilizados: "frequência de visitas ao varejista, compras e percentual de compras por cliente". Os resultados mostraram que participantes de programas de fidelidade são mais fiéis, comportamental e afetivamente, que os não participantes.

Sobre fidelidade no segmento de restaurantes, segundo pesquisa da Delloite (2014) realizada nos Estados Unidos, um-quarto (25\%) dos clientes considera o programa de fidelidade importante quando escolhe um restaurante. Metade dos entrevistados (50\%) disseram pertencer pelo menos a um programa de fidelidade, uma taxa muito inferior se comparada com de outros setores, como empresas áreas (78\%) e hotéis (70\%). 
Em outra pesquisa sobre o tema, Hobbs e Rowley (2008) coletaram dados para investigar a relação entre cartões de desconto de Pubs no Reino Unido e concluíram que este programa não gerava nem fidelidade comportamental nem atitudinal de forma direta, porém, indiretamente. Estes descontos geraram um efeito 'manada' (que o autor chamou de 'flocking behavior', que significa um grupo de pássaros voando juntos) de forma que a popularidade dos pubs aumentou. A conclusão do autor foi de que os cartões de desconto geram fidelidade comportamental e atitudinal de forma indireta.

\subsection{MERCADO BRASILEIRO DE FOOD SERVICE}

O segmento food service vem crescendo de forma consistente no mercado brasileiro. Em 2015, 33\% do consumo alimentício da população brasileira foi feito fora de casa - em 1995, esse número era de 19\%, um crescimento vertiginoso e sólido, que aponta para o potencial de desenvolvimento deste mercado. Segundo estimativa do Ibope (2014), o gasto com alimentação fora do lar no Brasil pode chegar a 38\% (Ibid). Este percentual é uma média, no Sudeste brasileiro esses patamares são ainda maiores devido ao perfil socioeconômico. Observa-se por classe social uma considerável diferença: a classe ' $A$ ' aplica $51,2 \%$ de seus gastos com a alimentação em restaurantes, enquanto que a classe 'E' dedica apenas $18 \%$.

Mesmo com um significativo destaque na economia nacional, o food service ainda tem grande potencial de expansão se comparado à Europa e Estados Unidos, onde são destinados de $50 \%$ a $60 \%$ do consumo de alimentos à alimentação fora do lar. Nos Estados Unidos há mais ou menos a mesma quantidade de estabelecimentos que no Brasil, cerca de um milhão, mas o faturamento é cinco vezes maior, o que denota um volume de refeições servidas muito superior (IFB, 2015).

O IFB (2015) realizou entrevistas com cinco mil consumidores em 2014, que revelaram dados importantes. A frequência com que o brasileiro realiza refeições fora de casa está entre as menores do mundo, com 1,3 vezes/dia, tomando apenas aqueles que afirmam ter realizado refeições fora de casa. Uma constatação relevante, que desfaz qualquer mito sobre a associação direta do food service com o lazer e o entretenimento, é que o 
consumo ocorre prioritariamente nos dias de semana (mais de $70 \%$ ) e o principal momento de refeição é o almoço, com mais de $34 \%$ de todas as refeições do dia todo. Destaca-se também uma forte incidência de pessoas que consomem também um lanche da tarde, que já aparece como o segundo momento mais importante do dia no consumo fora do lar.

Entre as principais razões que levam um consumidor a escolher os locais em que realiza suas refeições em restaurantes, o relacionamento e a conveniência estão entre as três mais frequentes motivações, com afirmações como "gosto de lá", "a localização é conveniente" e "sempre vou lá", basicamente as mesmas de outros países em que o food service é mais desenvolvido. O gasto médio por refeição é de $R \$ 14,39$ (Classe $A$ : $R \$ 20,02$; B: $R \$ 15,08$; e C: $R \$ 11,47)$.

\subsection{MERCADO BRASILEIRO DE INTERNET MÓVEL}

O exponencial aumento das vendas de smartphones amplia as possibilidades e as soluções, como funcionalidades adicionais ao processo básico de acúmulo de pontos, podendo citar: funcionalidade de notificação de usuários sobre ofertas especiais de seus restaurantes ou pratos favoritos; funcionalidade de feedback, ou seja, clientes podem compartilhar recomendações e comentários sobre o restaurante no aplicativo; e funcionalidade de geolocalização, em que o usuário tem a possibilidade de encontrar restaurantes participantes presentes em seu entorno, com informações úteis como telefone e horário de funcionamento (Silva, 2016).

Para entender a relação do brasileiro com estas tecnologias, apresentam-se números da pesquisa da CETIC (2013), que revela que 31\% dos brasileiros são usuários de Internet pelo telefone celular, uma estimativa de 52,5 milhões de usuários de Internet no celular - cerca de 18,6 milhões de indivíduos a mais do que o verificado no ano anterior. Estes usuários estão mais concentrados entre jovens da faixa etária de 16 a 24 anos (61\%) e pessoas com Ensino Superior (60\%), além disso, seguindo a tendência observada em outros indicadores de uso de TIC, indivíduos com 45 a 59 anos $(11 \%)$ e com 60 anos ou mais (3\%) utilizam em menor proporção a Internet 
no celular. A pesquisa também cita que $23 \%$ baixam aplicativos no celular, a maioria na faixa até 34 anos (ibid).

\subsection{TIPOLOGIA DE PROGRAMAS DE FIDELIDADE EM RESTAURANTES}

Os programas de fidelização, que oferecem recompensas financeiras, podem ser divididos em três principais modelos de negócio, que chamaremos ao longo do trabalho de 'Compra Coletiva', 'Clube de Vantagem' e 'Recompensa por Recompra', conforme detalhado a seguir:

\subsubsection{Programas do Tipo Compra Coletiva}

Como principais exemplos citam-se a empresa norte-americana Groupon ou a pioneira no Brasil Peixe Urbano. Este modelo de negócio se caracteriza por exibir uma oferta de produto de tempos em tempos. Para restaurantes, a oferta mostra a descrição detalhada da refeição oferecida, o preço normal e o desconto dado pelo restaurante. O cliente compra este cupom de desconto no site e tem um determinado período para utilizar (Koziolek \& Pires, 2011).

\subsubsection{Programas do Tipo Clube de Vantagens}

Como exemplos podemos citar as empresas Grubster, ChefsClub e Oclubegourmet. Neste modelo de negócio, o cliente paga uma mensalidade ( $R \$ 10$ a $R \$ 15 /$ mês em média) e recebe um cartão que the dá direito a descontos (de $25 \%$ a $50 \%$ em média) em restaurantes conveniados (Grubster, 2015).

\subsubsection{Programa de Recompensa por Recompras}

Neste modelo de negócio, o cliente acumula pontos a cada vez que consome no restaurante, após acumular, por exemplo, dez pontos, pode trocar por uma recompensa, geralmente uma refeição. Há implantações deste modelo em aplicativos para celular ou também em cartões de papel que são 
carimbados a cada ponto adquirido. Algumas empresas têm algum destaque neste mercado como Collact, GuidoCard e Bonuz. Este modelo possui um processo principal que é a etapa de acumular o ponto após efetivar uma compra (Collact, 2015), tal processo pode ser implantado basicamente de três maneiras:

- Aplicativo do celular. O cliente instala o aplicativo em seu smartphone, através deste aplicativo é possível digitalizar um comprovante da compra (a nota fiscal ou qualquer outro código fornecido pelo restaurante para identificar aquela compra) e assim acumular o ponto.

- Cartão em papel. Cartão fornecido pelo restaurante, que será carimbado ou adesivado a cada compra.

- Terminal/Tablet. A cada compra, o cliente informa sua identificação (CPF, por exemplo) que é digitado em um terminal do restaurante (um tablet, por exemplo) e com isso acumula o ponto. Neste modelo o cliente pode acompanhar sua pontuação através da internet.

O trabalho consistiu em aplicar uma pesquisa de natureza inferencial para responder aos objetivos específicos elencados no primeiro capítulo. Para coletar os dados aplicou-se um questionário com uma abordagem quantitativa do tipo ad hoc, ou sob medida. Para mensurar o tamanho do mercado de fidelização de restaurantes, definiu-se como universo de interesse os cidadãos das cidades do Rio de Janeiro e São Paulo que possuem smartphones com conexão com a internet, e estas questões foram adicionadas ao questionário, para eliminar respostas que não estivessem no universo pesquisado.

De acordo com Malhotra (2001), amostra é um subgrupo de uma população selecionado para participação no estudo, ou seja, o planejamento de uma amostragem começa com a especificação de uma população-alvo, que deve ser definida com qualidade através de características como: precisão (exatidão dos resultados); eficiência (medida de comparação entre diversos 
projetos amostrais); correção (grau de ausência de vieses não amostrais na amostra).

Para calcular a amostra $n$, utilizou-se as seguintes premissas (Aaker, Kumar \& Day, 2004):

$$
n=\frac{\left(S^{2} \times Z^{2} \times N\right)}{\left(S^{2} \times Z^{2}+e^{2} \times(N-1)\right)}
$$

Onde:

$S^{2}=\mathbf{0 , 2 5}$, sendo $S$ a variância, uma medida de dispersão, ou seja, o grau de diferença entre um indivíduo e outro em relação a sua atitude quanto ao tema de interesse. A variância baseia-se no quanto uma resposta difere da média da população. Como a variância não é conhecida, estima-se a maior variância possível numa proporção de 50\% favoráveis e 50\% desfavoráveis em relação ao que está sendo analisado, logo $0,5^{2}$ é igual a 0,25 (Ibid).

$\mathbf{N}=3,3$ Milhões, é o tamanho do universo a ser estudado. A população com smartphone conectado à internet nas cidades de Rio de Janeiro e São Paulo, conforme cruzamento de dados de pesquisa (Kantar, 2014) que afirma que $18 \%$ da população possui smartphone conectados à internet, multiplicado pelo tamanho das populações das cidades de Rio de Janeiro (6.453.682 de habitantes) e São Paulo (11.895.893 de habitantes) (IBGE, 2014) somado, encontra-se o valor de 3.302.924 pessoas $(18349575 \times 0,18)$.

e $=6,6 \%$, valor de tolerância do resultado da pesquisa (erro amostral), definido pelo autor, para tornar operacionalmente viável a coleta de dados para esta pesquisa. Para alcançar este erro, foram necessárias 220 respostas válidas. Pela lei dos grandes números, se um evento de probabilidade $\mathrm{p}$ é observado repetidamente em ocasiões independentes, a proporção da frequência observada deste evento em relação ao total número de repetições converge em direção a $\mathrm{p}$ à medida que o número de repetições se torna arbitrariamente grande (Durrett, 2010), ou seja, observou-se que acima de 220 respondentes seria necessária uma quantidade muita alta de respondentes para alcançar pequenas reduções no erro, por exemplo, para obter $5,6 \%$ de erro ( $1 \%$ a menos), seria necessário 306 respostas válidas (mais 86 respondentes, ou 39\% a mais de respondentes) o que aumentaria o 
esforço do processo de coleta de dados, sem grandes ganhos na precisão da amostra, por isso definiu-se 220 como um número adequado.

Índice $\mathbf{Z}=\mathbf{1}, \mathbf{9 6}$, que representa um intervalo de confiança de 95\%, que segundo Aaker et al. (2014), é um intervalo aceitável para pesquisas de mercado.

Portanto, conforme já detalhado, definiu-se como objetivo obter 220 respostas válidas por considerar que esta quantidade forneceria um erro e um intervalo de confiança adequado, segundo autores (Ibid). Os dados foram coletados de 15 até 18 de fevereiro de 2015.

Realizou-se um pré-teste, utilizando uma amostra por conveniência com 10 indivíduos dos mais variados perfis, para validação da assertividade do questionário. Os voluntários participantes do pré-teste não participaram das respostas válidas.

Elaborou-se o questionário Google Forms, que foi distribuído na internet. Foram utilizadas perguntas fechadas, perguntas de múltipla escolha, perguntas de caracterização e perguntas com escalas de avaliação, de acordo com a necessidade. O questionário resumido se encontra no apêndice 1 .

\subsection{COLETA DE DADOS}

Realizou-se na pesquisa uma entrevista pela internet, por meio da ferramenta Google Forms. O método descrito foi escolhido devido aos seguintes fatores: acesso a um grande número de pessoas; velocidade em compilar os dados; além de possibilidade de obter amostras da população com um foco específico, no caso, indivíduos com smartphone com internet. Para atingir tal público, utilizou ferramentas de comunicação como Twitter, Facebook, LinkedIn e WhatsApp para distribuir o questionário. Ferramentas tipicamente acessadas pelo smartphone e redução de custos, foram fatores chave pelo qual este método foi selecionado.

Pode-se considerar que se utilizou uma amostra por conveniência por ter sido aplicado um questionário pela internet. O perfil socioeconômico da amostra segue abaixo, na tabela 1 . Pode-se notar que o perfil da amostra é composto em sua maioria por indivíduos do sexo feminino, de 25 a 34 anos, solteiro(a), trabalhador, com renda mensal de 3 a 6 salários mínimos. 


\section{Tabela 1 - Perfil socioeconômico da amostra}

\begin{tabular}{|c|c|c|c|c|c|c|c|c|}
\hline \multirow{2}{*}{ Gênero } & \multicolumn{4}{|c|}{ Masculino } & \multicolumn{4}{|c|}{ Feminino } \\
\hline & \multicolumn{4}{|c|}{$42,4 \%$} & \multicolumn{4}{|c|}{$57,6 \%$} \\
\hline \multirow{2}{*}{$\begin{array}{l}\text { Faixa Etária } \\
\text { (em anos) }\end{array}$} & 12 a 17 & 18 a 24 & 25 a 34 & 35 a 44 & 45 a 54 & 55 a 64 & & 65 a 74 \\
\hline & $1,5 \%$ & $29,1 \%$ & $37,0 \%$ & $16,8 \%$ & $7,9 \%$ & $4,9 \%$ & & $3,0 \%$ \\
\hline \multirow[t]{2}{*}{ Estado Civil } & \multicolumn{2}{|c|}{ Solteiro(a) } & \multicolumn{2}{|c|}{$\begin{array}{l}\text { Casado(a) ou em união } \\
\text { estável sem filhos }\end{array}$} & \multicolumn{2}{|c|}{$\begin{array}{l}\text { Casado(a) ou em união } \\
\text { estável com filhos }\end{array}$} & & $\begin{array}{l}\text { Divorciado(a) } \\
\text { outros }\end{array}$ \\
\hline & \multicolumn{2}{|c|}{$55,2 \%$} & \multicolumn{2}{|c|}{$17,2 \%$} & \multicolumn{2}{|c|}{$23,2 \%$} & & $4,4 \%$ \\
\hline \multirow{2}{*}{ Principal Ocupação } & Trabalhador & Estudante & Desempregado & \multicolumn{2}{|c|}{ Aposentado } & \multicolumn{2}{|c|}{ Empresário } & Outros \\
\hline & $63,1 \%$ & $21,7 \%$ & $2,5 \%$ & \multicolumn{2}{|c|}{$5,9 \%$} & \multicolumn{2}{|c|}{$4,9 \%$} & $2,0 \%$ \\
\hline \multirow{2}{*}{$\begin{array}{c}\text { Renda mensal per capita } \\
\text { (em salários mínimos) }\end{array}$} & até 3 & 3 a 6 & 6 a9 & 9 a 12 & 12 a 15 & \multicolumn{2}{|c|}{$>15$} & - \\
\hline & $11,8 \%$ & $21,2 \%$ & $16,8 \%$ & $17,3 \%$ & $14,3 \%$ & \multicolumn{2}{|c|}{$24,1 \%$} & $2,0 \%$ \\
\hline
\end{tabular}

Fonte: Os autores (2015)

\subsection{ANÁLISE DOS DADOS}

A coleta de dados gerou variáveis e o objetivo do presente trabalho era entender como estas se correlacionam, através de testes de hipóteses e grau de determinação que uma variável ou um modelo exerce sobre uma determinada variável 'resultado'.

Para quantificar a dependência de um resultado $y_{1}$ em relação a um grupo de variáveis $x_{n}$ utilizou-se a ferramenta de regressão simples e múltipla, observando os coeficientes de correlação R múltiplo, R quadrado (regressão simples) e R-quadrado ajustado, que representam respectivamente o coeficiente de correlação e o coeficiente de determinação do modelo. Quanto mais próximo de 1 estes valores se encontram, mais podemos afirmar que o modelo estatístico explica o fato real. Abaixo a equação de regressão múltipla, onde $\beta$ é o coeficiente de cada variável e $\varepsilon$ o erro residual (Anderson, 2013).

$$
y_{1}=\beta_{1} x_{1}+\beta_{1} x_{1}+\cdots+\beta_{p} x_{i p}+\varepsilon_{i}
$$

A análise de variância foi utilizada para decidir se as diferenças amostrais observadas são reais (causadas por diferenças significativas nas populações observadas) ou casuais (decorrentes da mera variabilidade amostral). Portanto, essa análise parte do pressuposto que o acaso só produz pequenos desvios, sendo as grandes diferenças geradas por causas reais, possibilitando afirmar dependência entre as variáveis. 
Os pressupostos básicos para se executar a análise de variância são que as amostras são aleatórias e independentes, as populações têm distribuição normal (o teste é paramétrico) e as variâncias populacionais são iguais, porém, na prática, esses pressupostos não precisam ser todos rigorosamente satisfeitos. Os resultados são empiricamente verdadeiros sempre que as populações são aproximadamente normais e têm variâncias próximas, o que é o caso da amostra por conveniência utilizada no presente trabalho (Milone, 2009).

A análise de variância no Excel é realizada através da tabela ANOVA gerada através do cálculo de regressão múltipla na ferramenta de análise de dados. Observa-se principalmente o valor-P para definir se a hipótese de dependência de variáveis é válida, onde quanto menor o valor- $P$, mais determinada variável $x_{n}$ explica o resultado $y_{1}$ (Lapponi, 2005).

\subsection{APRESENTAÇÃO DOS RESULTADOS}

Os resultados foram apresentados dividindo por 4 faixas de renda sempre que necessário: de até 3 salários mínimos, de 3 a 9 salários mínimos, 9 a 15 salários mínimos, mais de 15 salários mínimos. Também buscou-se dividir entre os programas de fidelização mais pertinentes. Assim dividiu-se os resultados nas seguintes abordagens: (i) participação e avaliação por programa, (ii) Participação em programas de fidelidade, por renda, (iii) Participantes dos Principais Programas de Fidelidade, (iv) intenção de participar do programa de fidelidade, por renda e (v) Participa, Recompra, Recomenda, Intenção, aplicativo e redes sociais, por renda.

\subsection{SUMÁRIO DA METODOLOGIA}

A metodologia apresentada acima teve como propósito fornecer esclarecimentos sobre como foram obtidos e tratados os dados que serviram de insumo para os resultados que serão apresentados nos capítulos seguintes. O Quadro 1 contém a síntese dos procedimentos metodológicos desta pesquisa. 


\begin{tabular}{|c|l|l|}
\hline$\#$ & \multicolumn{1}{|c|}{$\begin{array}{c}\text { Abordagem } \\
\text { Metodológica }\end{array}$} & \multicolumn{1}{c|}{ Procedimento } \\
\hline $\mathbf{1}$ & Natureza & Exploratória \\
\hline $\mathbf{2}$ & Método & Survey \\
\hline $\mathbf{3}$ & Abordagem & Quantitativa ad hoc \\
\hline $\mathbf{4}$ & Tipo de Amostragem & $\begin{array}{l}\text { Amostra por conveniência não } \\
\text { assimétrica }\end{array}$ \\
\hline $\mathbf{5}$ & Fonte de Dados & $\begin{array}{l}\text { Primária - Questionário eletrônico } \\
\text { disponibilizado na internet }\end{array}$ \\
\hline $\mathbf{6}$ & Tratamento de Dados & $\begin{array}{l}\text { Regressão Linear e Teste de Hipótese } \\
\text { Anova }\end{array}$ \\
\hline $\mathbf{7}$ & Análise de Dados & $\begin{array}{l}\text { Estatística descritiva utilizando MS } \\
\text { Excel }\end{array}$ \\
\hline
\end{tabular}

\section{Quadro 1: Síntese dos Procedimentos Metodológicos}

Fonte: Os autores (2015)

\section{RESULTADOS}

Após análise dos dados coletados na pesquisa quantitativa com 220 respostas válidas, o objetivo central da pesquisa foi atingido: quantificar, definir perfil e classificar preferência dos consumidores adeptos, ou com potencial à adesão, a soluções de fidelização para restaurantes. $A$ seguir os resultados da pesquisa são apresentados em detalhe, agrupados de acordo com cada objetivo específico.

\subsection{AVALIAR A RECEPTIVIDADE DOS CONSUMIDORES AOS PROGRAMAS DE FIDELIDADE DE RESTAURANTE.}

O primeiro dado relevante a ser apresentado é a receptividade dos entrevistados aos programas do tipo Compras Coletivas, Clube de Vantagens e Recompensa por Recompras. Esta receptividade é medida em uma escala de 1 a 5 , onde 5 indica que o entrevistado é totalmente interessado e 1 indica totalmente desinteressado por determinado programa. Apresenta-se também a adesão a cada programa, lembrando que um mesmo indivíduo pode participar de nenhum ou até todos os programas. 


\section{Tabela 2 - Participação e avaliação por programa}

\begin{tabular}{|c|c|c|c|}
\cline { 2 - 4 } \multicolumn{1}{c|}{} & Coletiva & Clube & Recompra \\
\hline \% de Participantes & $56 \%$ & $18 \%$ & $24 \%$ \\
\hline Avaliação média (1 a 5) & 2,52 & 2,13 & 2,74 \\
\hline
\end{tabular}

Fonte: Os autores (2015)

O programa do tipo Recompensa por Recompra desperta maior interesse (média de 2,74 em escala de 1 a 5) e o modelo mais popular até o momento é o de Compras Coletivas, utilizado por 56\% dos indivíduos da amostra.

\subsection{CORRELACIONAR A RECEPTIVIDADE DOS CONSUMIDORES POR PROGRAMAS DE FIDELIDADE DE DIVERSOS SEGMENTOS COM A RECEPTIVIDADE PARA ESTAS ESTRATÉGIAS NO SEGMENTO DE RESTAURANTES.}

Perguntou-se aos entrevistados em quais segmentos participavam de programas de fidelidade. Listou-se como possíveis 12 respostas: (i) Hotel, (ii) Companhia área, (iii) Cartão de crédito, (iv) Restaurante, (v) Loja de Departamento, (vi) Posto de Gasolina, (vii) Supermercado, (viii) Aluguel de Carro, (ix) Farmácia, (x) Livraria e Informática, (xi) Programas de Fidelidade e (xii) Outros.

Cada coluna na figura 2 representa a porcentagem de indivíduos da amostra que participa do programa de fidelidade de cada segmento (hotel, cia. aérea, etc.). Há também quatro agrupamentos por renda (em salários mínimos) para identificar a correlação de adesão com a renda dos respondentes. Cada uma das 12 possíveis respostas, nos quais os respondentes deveriam responder de acordo com sua participação foram separadas por faixas de renda. As porcentagens sobre a barra representam a proporção que participa do programa de fidelidade. A barra vermelha, representa a participação da cia. aérea, a barra verde do cartão de crédito e a lilás de restaurantes.

Calculando uma regressão linear simples, representada pelas linhas da figura 2 , observa-se que a adesão a programas de fidelidade de companhias 
áreas é fortemente determinada pela renda $\left(R^{2}=0,99\right)$. Para cartões de crédito a renda também é a principal variável, com coeficiente de determinação $R^{2}=0,95$. Para restaurantes esta curva de regressão linear já apresenta um $R^{2}=0,84$, o que significa que a adesão a programas de fidelidade de restaurante é mais complexa, sendo determinada por um composto mais amplo de variáveis do que simplesmente a renda.

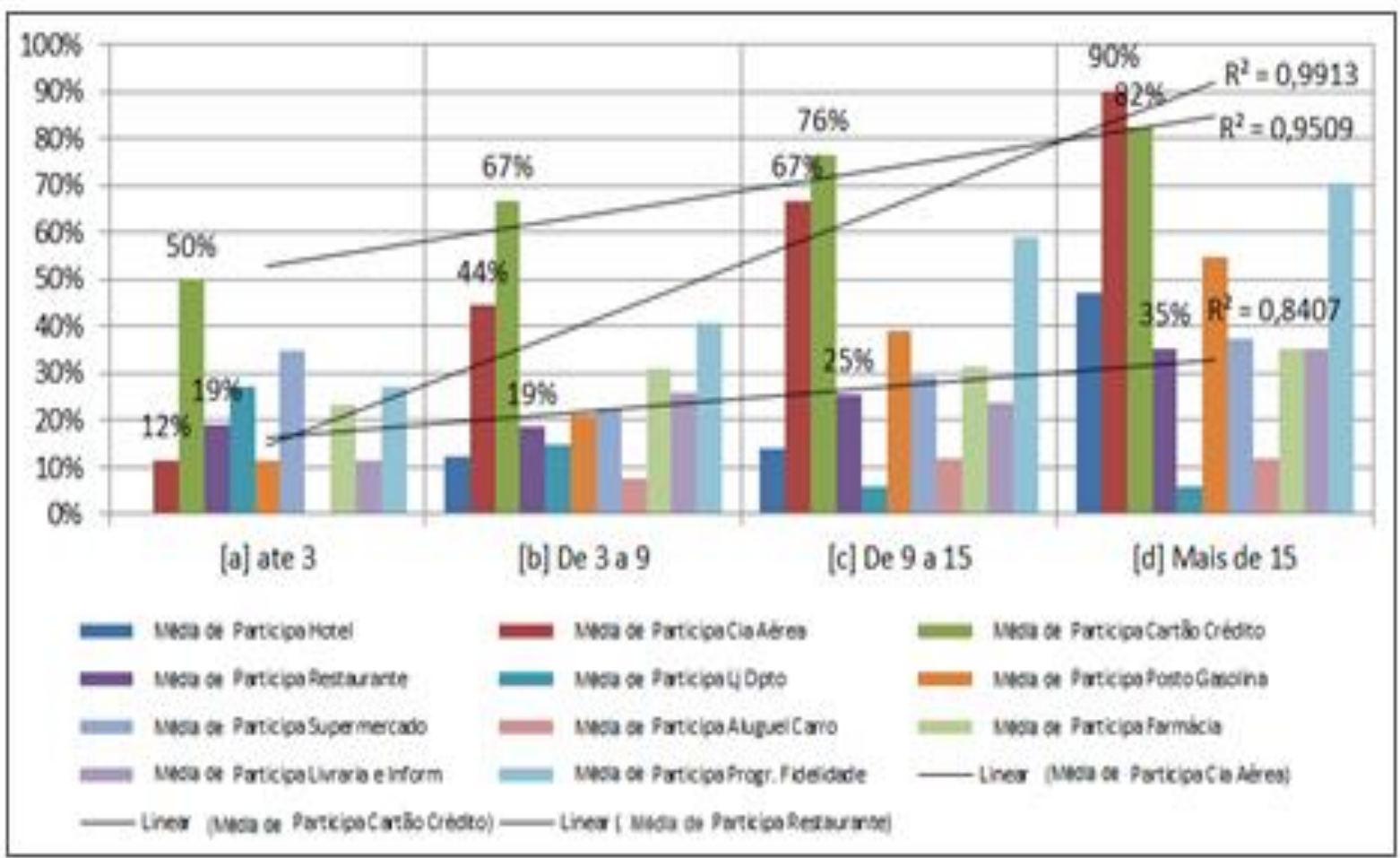

Figura 2: Participação em programas de fidelidade, por renda (em Salários Mínimos)

Fonte: Os autores (2015)

Numa visão consolidada dos participantes de programas de fidelidade sem a quebra por renda, conforme tabela 3, observa-se que o segmento de restaurante não obteve o mesmo patamar de participação $(23 \%)$ de outros segmentos já consolidados, como companhia aérea (56\%), cartão de crédito (70\%) e posto de gasolina (32\%).

Tabela 3 - Participantes - Principais Programas de Fidelidade

\begin{tabular}{llll}
\hline Cia Aérea & Cartão Crédito & Restaurante & Posto Gasolina
\end{tabular}


Fonte: Os autores (2015)

Quanto as perguntas sobre programas de fidelidade, solicitou-se listar os programas que o entrevistado ainda não participa, porém há intenção de participar, com isto montou-se a figura 3 a seguir, nos mesmo moldes do anterior, também com a porcentagem de indivíduos com a intenção de participar em cada programa, com agrupamento por renda. Nos três primeiros seguimentos de renda os resultados apontam que o maior interesse é pela participação de programas ligados a Cia. Aéreas, o resultado não está presente no seguimento de maior renda, uma vez que um número significativo de respondentes já participou deste tipo de programa de fidelidade. Os programas de fidelidade para restaurantes ficaram em segundo lugar na intenção de participação, com resultados de $19 \%$, 36\%, 31\%, 31\%, respetivamente de acordo com faixas de rendas.

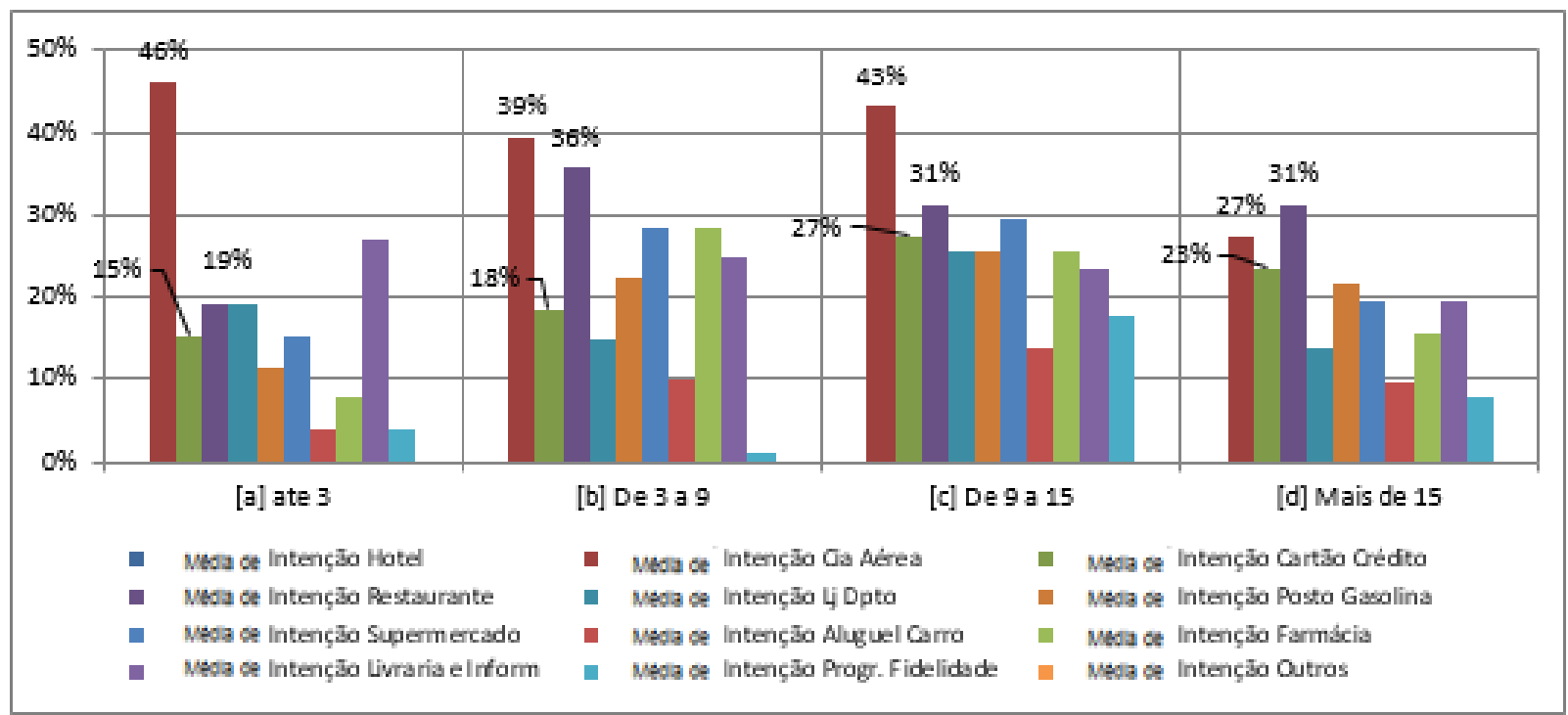

\section{Figura 3: Tem intenção de participar do programa de fidelidade, por renda (salários mínimos)}

Fonte: Os autores (2015)

Neste gráfico observa-se que os programas de fidelização de restaurante, junto com os de companhias aéreas, possuem o mais alto percentual de indivíduos com a intensão de participar.

Solicitou-se aos entrevistados para classificar de 1 a 5, o quanto estaria disposto a instalar um aplicativo (no smartphone) para participar do programa 
de fidelização de um restaurante que frequenta, e se divulgaria este restaurante para amigos e conhecidos através de redes sociais em troca de recompensas. Novamente agrupou-se o resultado em quatro grupos de renda para perceber a influência desta variável nas respostas e obteve-se o gráfico da figura 4 a seguir. Os resultados foram separados por faixas de renda. As barras representam o percentual dos respondentes que participa, recompra, recomenda ou tem intenção de participar de programas de fidelidade de restaurantes. A linha azul representa a predisposição, numa escala de 1 a 5, em baixar um aplicativo para participar de um programa de fidelização. A linha vermelha representa a predisposição, também na faixa de 1 a 5 , de divulgar restaurantes através de redes sociais em troca de recompensas.

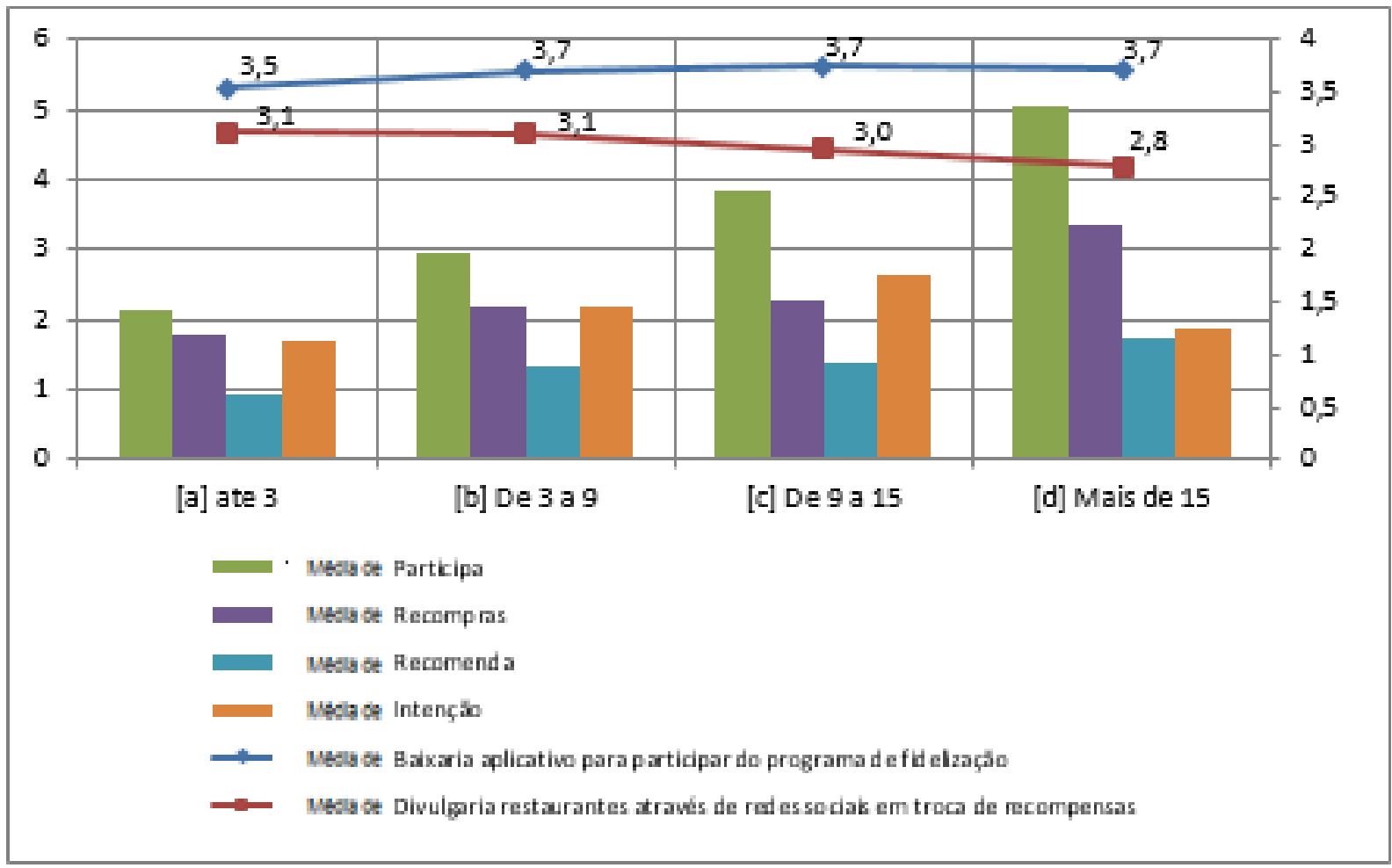

\section{Figura 4: Participa, Recompra, Recomenda, Intenção, aplicativo e redes sociais, por renda (salários mínimos)}

Fonte: Os autores (2015)

Pode-se denotar que a variável renda influencia negativamente a prédisposição a se expor em redes sociais divulgando um restaurante para ganhar recompensas. Quanto se baixaria o aplicativo para participar do programa de fidelização, observa-se um leve crescimento das médias entre o grupo de 3 
salários mínimos até 9, e uma estabilização em patamar de 3,7 à medida que a renda avança.

\subsection{IDENTIFICAR O GRAU DE FIDELIZAÇÃO (COMPORTAMENTAL E} ATITUDINAL) QUE OS PROGRAMAS TÊM POTENCIAL PARA ALCANÇAR.

Fez-se a seguinte pergunta: "Você possui o hábito de comprar para acumular os benefícios do programa de fidelidade mesmo que você considere um outro concorrente mais vantajoso (em preço/qualidade)?". Novamente as respostas foram agrupadas por renda (de 'Até 1 salário mínimo' à 'Mais de 15 salários') e observou-se que quanto maior a renda, mais se responde 'sim' a esta pergunta, o que parece indicar que a medida que a renda do público aumenta, maior é a possibilidade de se utilizar programas de fidelização. Os resultados estão demonstrados na figura 5 abaixo.

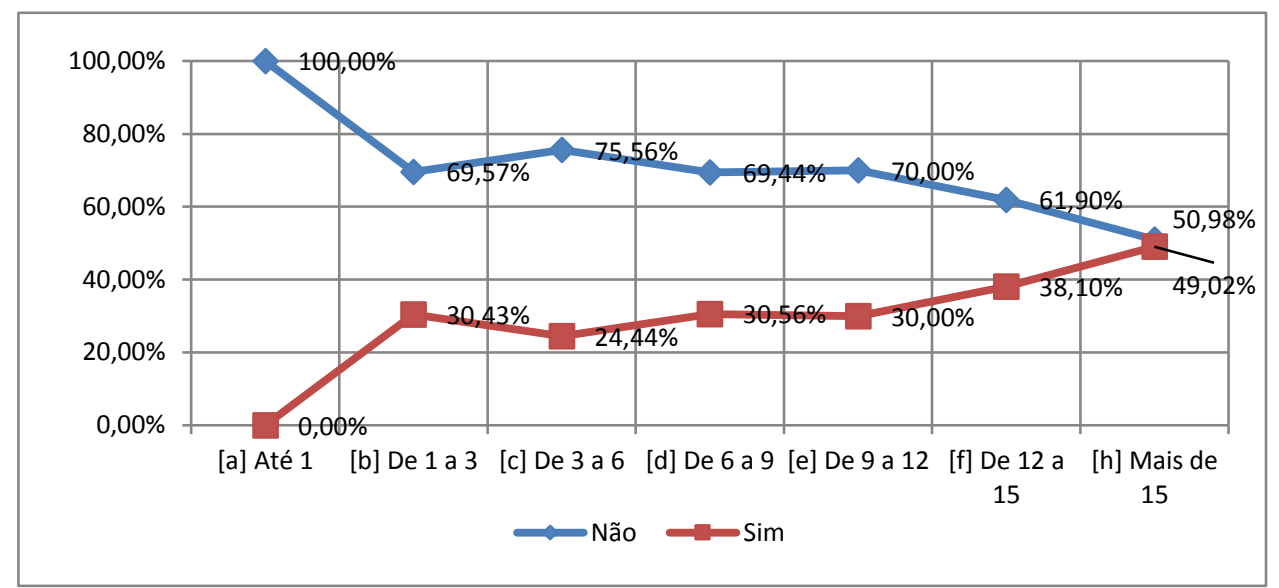

\section{Figura 5: Compra pelos benefícios do programa, mesmo com ofertas agressivas da concorrência}

Fonte: Os autores (2015)

Perguntou-se com qual frequência o entrevistado realiza recompras em restaurantes nos quais participa de programa de fidelidade. Considerando apenas os entrevistados que tem hábito de recompra montou-se a figura 6 abaixo, que denota que a fidelização comportamental ainda precisa ser mais bem trabalhada pelos restaurantes, uma vez que o comportamento de recompra acontece predominantemente de 1 a 5 vezes por semestre, apenas. 


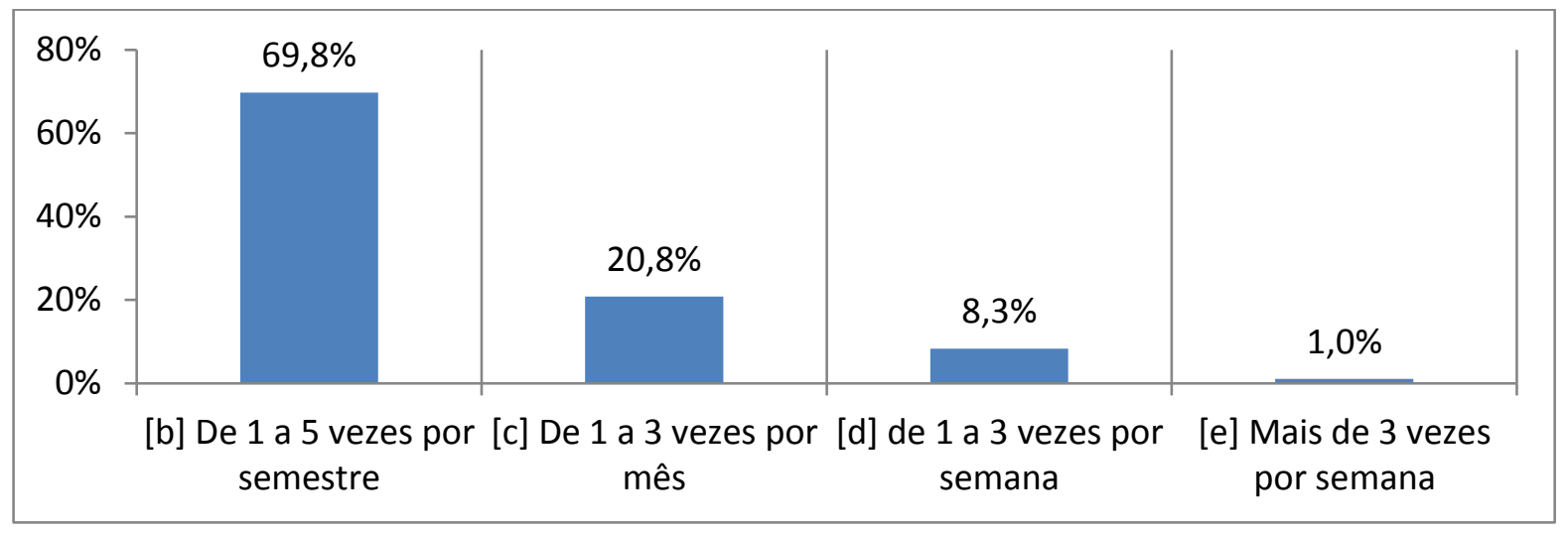

Figura 6: Comportamento de recompra

Fonte: Os autores (2015)

Para compreender a fidelização comportamental e atitudinal em uma visão consolidada, apresenta-se, a figura7 a seguir, a taxa percentual de respondentes que realizam recompra (fidelização comportamental) e recomendam (fidelização atitudinal) a empresa do qual participam do programa de fidelidade. Também se agrupou em quatro faixas de renda.

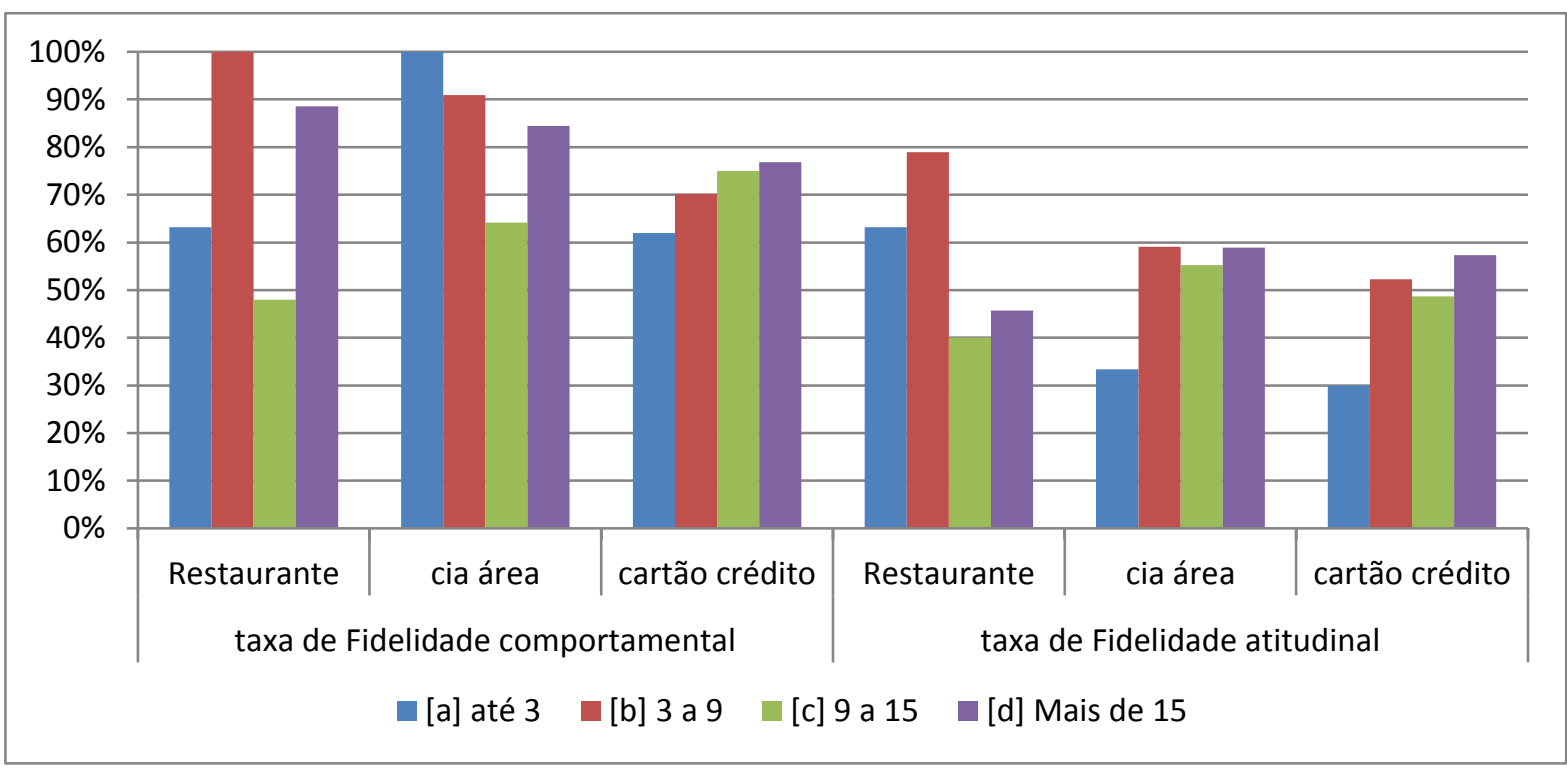

\section{Figura 7: Taxa de fidelidade comportamental e atitudinal (agrupados por segmento e por renda em salários mínimos)}

Fonte: Os autores (2015)

Fica evidente, observando o gráfico apresentado, que todos os segmentos conseguem atingir mais fidelidade comportamental que atitudinal, porém uma porcentagem considerável de fidelidade atitudinal é atingida tanto 
para o segmento de restaurantes quanto para companhias aéreas e cartões de crédito.

O histograma abaixo mostra que, dos 220 entrevistados, 51(23\%) participam de programas de fidelidade para restaurantes, destes, 41 realizam recompras nos restaurantes aos quais participam do programa e 28 recomenda o restaurante, $80 \%$ e $55 \%$ dos que participam de programas, respectivamente. Há 67 entrevistados que ainda não participam de programas de fidelidade para restaurantes, porém tem a intenção de começar a participar, o que representa outros $30 \%$ da amostragem total. Observa-se que somando os entrevistados que já participam com os que têm a intenção de participar, têm-se $53 \%$ da amostra, valor próximo ao número de integrantes de programas de fidelidade nos EUA, apresentado na pesquisa da Deloitte. Estes números indicam uma tendência a alcançar números similares aos norteamericanos em intervalo de tempo não muito longo, caso a tendência continue.

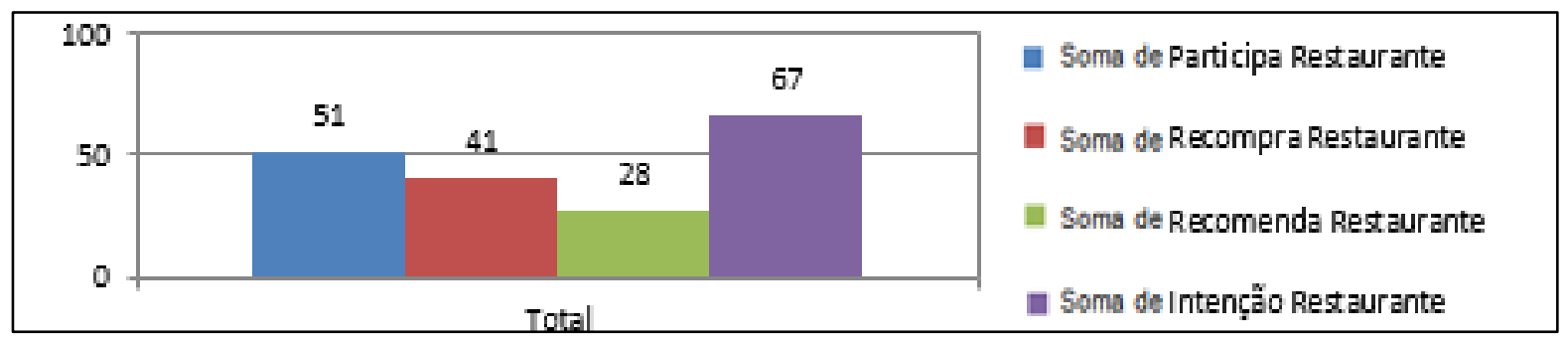

\section{Figura 8: Programa de Fidelidade para Restaurantes: Participa, Recompra, Recomenda e Intenção}

Fonte: Os autores (2015)

Assim como apontado por outros trabalhos (HOBBS, 2008, GÓMEZ, 2006), o presente trabalho concluiu que os consumidores não rejeitam programas de fidelidade em restaurantes. Estes, se bem trabalhados, podem criar fidelidade comportamental e atitudinal. Soluções digitais para este processo são bem vistas, principalmente na faixa etária abaixo dos 55 anos. As maiores rendas são mais interessadas neste tipo de programas, inclusive afirmando que compram em um estabelecimento mais desvantajoso em busca da recompensa da fidelidade (49\% para rendas per capita acima de 15 salários mínimos). 
O trabalho investigou, através de uma pesquisa predominantemente quantitativa, o perfil dos consumidores identificando características em comum entre os que são receptivos a programas de fidelidade em geral com os que são receptivos especificamente a programas de fidelidade de restaurantes. Identificou-se o grau de fidelização afetiva e comportamental que os programas têm potencial de alcançar, tanto para programas de fidelização de restaurantes como para os demais, permitindo comparação.

Percebeu-se que, assim como em outros estudos sobre programas de fidelidade em bares e restaurantes na Europa e nos EUA, o brasileiro das regiões pesquisadas também não apresenta aversão a programas de fidelização.

Entre os modelos específicos de programa para restaurantes analisados, compras coletivas, clube de vantagens e recompensa por recompras, o último demonstrou maior potencial de crescimento visto que é o modelo com maior aceitação na média total. Quando avaliado apenas entre os participantes do programa, a avaliação sobe.

Com relação ao perfil sócio econômico, a renda se mostrou a mais relevante variável para explicar os fenômenos de adesão a programas de fidelidade. Novamente os dados acompanham as pesquisas em outros países, que demonstram que as lideranças em programas de fidelidade ficam por conta dos segmentos pioneiros, companhias áreas e operadoras de cartões de crédito. Este dado, junto com a avaliação positiva dos usuários de programas de restaurantes $(3,36)$ é um indicador que este modelo tem espaço para mais crescimento no país, ainda mais quando comparado com o dado da pesquisa da Deloitte (2014) nos EUA, onde 50\% dos entrevistados já participavam de programas de fidelização de restaurante, enquanto no Brasil este número está em $23 \%$, conforme apresentado na tabela 3 do capítulo de resultados.

Assim como nas pesquisas de Dick e Basu (1994) e Gómez et al. (2006), o presente trabalho comprovou que programas de fidelidade são capazes de incrementar a fidelidade em suas duas dimensões: comportamental e atitudinal. Porém a existência de um programa de fidelidade 
é apenas uma variável de um conjunto amplo e complexo de variáveis que têm a capacidade de gerar fidelidade comportamental e atitudinal.

Soluções digitais para este processo são bem vistas, principalmente na faixa etária abaixo dos 55 anos. As maiores rendas são mais interessadas neste tipo de programas, inclusive afirmando que compram em um estabelecimento mais desvantajoso em busca da recompensa da fidelidade (49\% para rendas per capita acima de 15 salários mínimos).

Este fenômeno de programas de fidelização em restaurantes baseado em aplicativos de smartphone é incipiente, com poucas e jovens empresas competindo neste mercado, porém estão crescendo e tem muito potencial à medida que a receita do chamado food service cresce acima do PIB no Brasil. Diante deste contexto, algumas perguntas necessitam de uma análise qualitativa com clientes e gerentes de restaurantes, complementando a análise quantitativa do presente trabalho, para entender porque muitas pessoas ainda não participam de programas de fidelização de seus restaurantes favoritos e porque muitos restaurantes ainda não implantaram um programa de fidelidade. Entender qualitativamente o quanto de fidelidade atitudinal estes programas realmente geram. Entrevistas com gerentes e proprietários de restaurantes também poderiam sanar questões sobre como os restaurantes que já possuem uma solução de fidelização estão trabalhando para divulgá-la para seus clientes e como estes restaurantes estão utilizando a base de dados oferecida por programas baseados em soluções digitais para entender e se aproximar mais de seus clientes. 


\section{REFERÊNCIAS}

Aaker, D. A.; Kumar, V.; Day, G. S. (2004). Pesquisa De Marketing. 2 Ed. São Paulo: Atlas

ABIA (2014). Faturamento do segmento de Service Foods, Associação Brasileira das Indústrias da Alimentação. Acesso em 25 Fev. 2014. Disponível em <http://www.abia.org.br/vst/vendas.pdf>.

Anderson, D. R.; Sweeney, D. J.; Williams, T. A. (2013). Estatística aplicada à administração e economia. 3. ed. São Paulo: Cengage Learning.

Banco Central do Brasil (2014). Indicadores econômicos consolidados. Acesso em 25 Fev. 2014. Disponível em http://www.bcb.gov.br/?INDECO/.

CETIC (2013). Pesquisa TIC Domicílios. São Paulo, Comitê Gestor da Internet.

Collact (2015). Acesso em 27 Fev. 2015. Disponível em $<$ www.collact.com.br $>$.

Deloitte (2014) Deloitte Survey: Restaurant Loyalty Programs Need Spice. PR Newswire US. Mar. 31, 2014.

Dick, A.S.; Basu, K. (1994). Customer Loyalty: Toward an Integrated Conceptual Framework, Journal of the Academy of Marketing Science, Winter, 99-113.

Durrett, R. (2010). Probability: theory and examples. Cambridge university press.

Gómez, B. G.; Arranz, A. G.; Cillan, J. G. (2006). The role of loyalty programs in behavioral and affective loyalty. The Journal of Consumer Marketing, Santa Barbara, v. 23, n. 7, p. 387-396.

Google Forms (2015). Acesso em 25 Fev. 2015. Disponível em <https://www.google.com/forms/about/>.

Grubster (2015). Acesso em 27 Fev. 2015. Disponível em < www.grubster.com.br/assinar>.

Hobbs, R; Rowley J. (2008). Are pub discount cards loyalty cards? Journal of Consumer Marketing. 25, 6, 369-377, oct. 2008. issn: 07363761. 
IBGE (20014), Estimativa Populacional 2014, Instituto Brasileiro de Geografia e Estatística (1 de julho de 2014). Visitado em 29 de agosto de 2014.

IFB (2015). Números do segmento de Food Service no Brasil, Instituto Food Service Brasil. Acesso em 25 Fev. 2015. Disponível em <http://alimentacaoforadolar.com.br/ifb-instituto-de-food-service-brasildivulga-estudos-ineditos-sobre-o-segmento-no-pais/>.

FIESP (2015). Mesmo com crise, setor de alimentação continua a crescer no Brasil. Acesso em 20 jul. 2015. Disponível em <http://www.forbes.com.br/negocios/2015/06/mesmo-com-crise-setorde-alimentacao-continua-a-crescer-no-brasil/>.

Jensen, J. M.; Hansen, T. (2006). An empirical examination of brand loyalty. Journal of Product \& Brand Management, v. 15, n. 7, p. 442-449.

Kantar (2014). Pesquisa sobre uso do smartphone no Brasil, Kantar World Panel. Acesso em 22/02/2015. Disponível em <http://www.kantarworldpanel.com/br/Releases/Geracao-Y-e-a-quemais-usa-smartphone>.

Kotler, P.; Keller, K. L. (2012). Marketing Management. 14. Ed. New Jersey: Pearson Prentice Hall.

Koziolek, N.; Pires, T. (2011). Compras coletivas: a evolução do mercado online. Acesso em 15 jan. 2015. Disponível em <http://www.com.ufv.br/disciplinas/cibercultura/2011/04/comprascoletivas-a-evolucao-do-mercado-online/>.

Lapponi, J. C. (2005). Estatística usando excel. 4. ed. Rio de Janeiro: Campus.

Larán, J. A.; Spinoza, F. S. (2004). Consumidores satisfeitos, e então? Analisando a satisfação como antecedente da lealdade. Último acesso em: 25 jul $2015 . \quad$ Disponível em <http://www.scielo.br/scielo.php?script=sci_arttext\&pid=S1415$65552004000200004>$.

Malhotra, N. K. (2001). Marketing research: an applied orientation. 3 ed. Upper Saddle River: Prentice Hall.

Milone, G. (2009). Estatística Geral e Aplicada. São Paulo: Centage Learning, 2009. isbn 85-221-0339-9. Capítulo 12. 
Silva, V. A. (2016). Por que criar um aplicativo para restaurante? Último acesso em 15 abr $2016 . \quad$ Disponível em <https://blog.easyeasyapps.net/negocios/porque-criar-um-aplicativopara-restaurante/>.

TELECO (2015). Usuários de internet no Brasil. Acesso em 25 Fev. 2015. Disponível em <http://www.teleco.com.br/internet.asp>.

Terzian (2016). Na contramão da crise, setor de alimentação cresce sem parar. Último acesso em: 20 fev.2016. Disponível em <http://infood.com.br/nacontramao-da-crise-setor-de-alimentacao-cresce-sem-parar/>. 


\section{APÊNDICE 1}

Abaixo segue o resumo do questionário aplicado, que pode ser acessado na integra no link da ferramenta Google Forms <http://goo.gl/forms/pcyx8PIfCuoStxKm2 >.

\begin{tabular}{|l|}
\hline \multicolumn{1}{|c|}{ Resumo do Questionário Aplicado } \\
\hline Possui smartphone com acesso à internet \\
\hline Sexo \\
\hline Idade \\
\hline Estado Civil \\
\hline Ocupação \\
\hline Escolaridade \\
\hline Renda \\
\hline Cidade \\
\hline Possui hábito de instalar aplicativos \\
\hline Em quais segmentos participa de programas de fidelidade \\
\hline Em quais segmentos realiza recompra por causa do programa de fidelidade \\
\hline Possui o hábito de comprar somente para acumular o benefício \\
\hline Em quais segmentos realiza recomendações por causa do programa de fidelidade \\
\hline Em quais segmentos tem intensão de participar do programa de fidelidade \\
\hline Interesse por programas do tipo Compras Coletivas \\
\hline Interesse por programas do tipo Clube de Vantagens \\
\hline Interesse por programas do tipo Recompensa por Recompra \\
\hline Quais dos modelos de programa de fidelização em restaurante participa \\
\hline Divulgaria restaurante em rede social por recompensa \\
\hline Qual frequência realiza recompras em restaurantes \\
\hline Qual processo considera mais prático para o modelo Recompensa por Recompra \\
\hline Instalaria aplicativo para participar de programa de fidelidade de restaurante \\
\hline Avaliação de funcionalidades relevantes em uma solução baseado em aplicativo \\
\hline
\end{tabular}

